Fecha de entrega: 20 de octubre de 2010

Fecha de aprobación: 3 de noviembre de 2010

\title{
REVISIÓN CRÍTICA A LA PROPUESTA DE INTEGRACIÓN SOCIAL Y CULTURAL DE BERNARDO DE MONTEAGUDO EN SU DIÁLOGO ENTRE ATAHUALPA Y FERNANDO VII EN LOS CAMPOS ELÍSEOS (1809)*
}

\author{
CRITICAL REVIEW TO THE PROPOSAL OF SOCIAL AND CULTURAL \\ INTEGRATION OF BERNARDO DE MONTEAGUDO IN DIÁLOGO ENTRE \\ ATAHUALPA Y FERNANDO VII EN LOS CAMPOS ELÍSEOS (1809)
}

Manuel Leonardo Prada Rodríguez ${ }^{* *}$

\section{Resumen}

Bernardo de Monteagudo en su texto: Diálogo entre Atahualpa y Fernando VII en los Campos Eliseos, parte de una crítica a las atrocidades llevadas a cabo por los españoles contra los americanos en la Conquista -atrocidades que sobrepasan las llevadas a cabo por Napoleón contra Fernando VII-, para proponer una integración social y cultural que movilice a los pueblos latinoamericanos a la independencia del colonialismo español. Sin embargo, su propuesta no reivindica al indígena, sino que su imagen es usada por el escritor como símbolo de una Latinoamérica que se limita a los criollos. Es decir, el indígena quedará, luego de las independencias latinoamericanas, en una situación similar a la colonial, sólo que ahora bajo el dominio de los criollos. De igual manera, esto nos puede suceder en nuestra realidad bogotana: pensar que Latinoamérica, y especialmente Colombia, se reduce a los Andes, a las ciudades del interior, excluyendo así al Caribe.

Palabras clave

Colonialismo, independencia, exclusión, criollos, indígenas, integración.

\footnotetext{
* Artículo de investigación para el grupo Fray Bartolome de Las Casas.

** Magíster en Filosofía Latinoamericana de la Universidad Santo Tomás.
} 


\begin{abstract}
Bernardo de Monteagudo, through his Diálogo entre Atahualpa y Fernando VII en los Campos Eliseos (Dialogue between Atahualpa and Fernando VII in the Champs-Élysées), criticizes the outrageous acts commited by the Spaniards against the Latin Americans during the Conquest; atrocities that exceeded the ones by Napoleon against Fernando VII. He proposes a social and cultural integration that mobilizes Latin American people to independence from Spanish colonialism. Even though the writer uses the image of the indigenous as a symbol of a Latin America his proposal does not make a claim for them since from his perspective it is only for the criollos. Therefore, the indigenous people, after the Latin American independence, will be in a similar situation to the colonial one, but this time under the command of the criollos. This may also happen in our Bogotá: considering that Latin America, and especially Colombia, is limited to the Andes and interior cities, excluding in that way the Caribbean.
\end{abstract}

\title{
Keywords
}

Colonialism, independence, segregation, criollos, indigenous people, integration.

\section{Introducción}

El texto Diálogo entre Atahualpa y Fernando VII en los Campos Elíseos, además de ofrecer un esparcimiento por su estilo narrativo fresco, nos motiva la necesidad de integrar a nuestros pueblos latinoamericanos para lograr una independencia social y cultural, problema que nos aqueja de nuevo en esta época globalizada, cuyo sistema económico es el neoliberalismo llevado al extremo, el cual acrecienta las brechas duales entre ricos y pobres, amos y esclavos, victimarios y víctimas, entre otras categorizaciones hechas por filósofos de la liberación, como Enrique Dussel, para describir e interpretar la realidad latinoamericana.

Bien podríamos leer el texto de Monteagudo sin escudriñar quiénes fueron Atahualpa ${ }^{1}$ y El

1 Hermano de Huáscar, legítimo heredero del incario. Por órdenes de su papá, Huayna Cápac, Atahualpa quedó a cargo de la parte norteña del Tahuantinsuyu. Y por estar peleando con su hermano, por mostrar toda su gloria, se descuidó y no puso límite a la entrada de Fran-
Deseado $^{2}$, o dónde fue el lugar en el que se desarrolló el diálogo ${ }^{3}$, la tesis central puede

cisco Pizarro a Perú, quien lo secuestró y, aun habiendo recibido una gran cantidad de oro y plata a cambio de su libertad, lo mató.

2 Fernando VII, rey de España, destronado por Napoleón Bonaparte en la época de algunas independencias suramericanas.

3 "Los Campos Elíseos en la mitología griega (en griego antiguo 'H $\mathrm{\lambda} u ́ \sigma \iota \alpha \pi \varepsilon \delta i ́ \alpha)$ eran una sección subterránea sagrada de los Infiernos (Elíseo proviene de la palabra griega Elysion). Los Campos Elíseos, o a veces mencionados como las Llanuras Eliseanas, eran el lugar sagrado donde las sombras de los hombres virtuosos y los guerreros heroicos llevaban una existencia dichosa y feliz, en medio de paisajes verdes y floridos. Era la antítesis del Tártaro y a menudo se ha asociado con el Cielo cristiano. Aún así las personas que residían en los Campos Elíseos tenían la oportunidad de regresar al mundo de los vivos, cosa que no muchos hacían. Son el marco donde se desarrollan los Diálogos de los muertos, un género literario que gozó de gran desarrollo desde la Antigüedad (como Luciano en el siglo II d. C.) hasta el siglo XVIII" (http://es.wikipedia.org/wiki/Campos_El $\%$ C3\%ADseos_(mitolog $\% \mathrm{C} 3 \% \mathrm{ADa})$ ). 
resumirse así: Fernando VII se está quejando por las barbaridades que Napoleón ha cometido con su reino, y por este motivo cree ser el rey más desgraciado de España. Entonces, Monteagudo, en boca de Atahualpa -quien históricamente había muerto casi trescientos años antes-, aprovecha para decirle que no se queje, que no se considere a sí mismo una víctima, hasta no reconocer que su nación ha sido peor de victimaria con América de lo que Napoleón ha sido con España. Al darse cuenta de esto, El Deseado empieza a esgrimir pretextos a favor de España, que en seguida son un contraargumento a favor de Atahualpa. Al final, Atahualpa gana la disputa, incluso lo convence de motivar a América a la independencia. En este sentido, el texto permite una lectura agradable, pues, mediante una ficción literaria, Monteagudo anima, tanto al pueblo latinoamericano de su época como al de la actualidad, hacia la libertad. Pero, ¿será que Monteagudo, a través del personaje de Atahualpa, estaba pensando en la libertad de todas las personas que integran Latinoamérica?

\section{¿De qué se trata el texto?}

El diálogo tiene dos partes principales: la primera es el diálogo entre el inca y el rey español, y la segunda, el punto culminante donde Atahualpa nos invita a luchar por la independencia.

La primera parte, es decir, el diálogo entre Atahualpa y Fernando VII, comienza cuando el rey se queja de que Napoleón Bonaparte lo llevó preso a Francia, impidiéndole así gobernar, y muestra su deseo de que alguien le ponga freno a dicho emperador, para poder recobrar su reino ${ }^{4}$. En ese momento Atahualpa, enfáti-

4 "El segundo momento en los procesos de independencia de nuestra América es la separación de las colonias ibéricas continentales. También aquí Napoleón desempeñará un papel importante: ocupada la península ibérica por sus camente, le dice que entiende perfectamente su situación, por cuanto también la vivió. Y como desconociendo la historia, Fernando VII le dice que no entiende por qué compara lo terrible que hace Bonaparte con España, con lo que hicieron y hacen los españoles en América 5 . Es decir, el rey se ve a sí mismo como víctima, no se da cuenta que su nación también ha sido victimaria. A partir de ese momento, Atahualpa muestra situaciones respecto a la dominación española sobre Latinoamérica, comparando, todo el tiempo, el dolor que siente con el que vive Fernando VII por causa de Napoleón. Tales situaciones se pueden resumir así: el rey de España es tirano y reconocido en Latinoamérica como usurpador; España es ladrona y para saciar su sed de riqueza en Latinoamérica, hace correr ríos de sangre de indígenas, luego de haberlos esclavizado, separado de sus familias, hecho aguantar hambre, etc. Entonces, Fernando VII reconoce las cosas que España ha hecho, pero trata de justificarlas, diciendo que otros imperios también lo han hecho en la Antigüedad. Además, según el rey español, esas barbaries se cometieron por motivos de defensa propia, de conservación de la vida, a

tropas (a las que el pueblo español hostigará heroicamente con sus 'guerrillas', aportando de paso este vocablo al mundo), las colonias iberoamericanas empiezan a desgajarse de sus metrópolis por distintas vías (violentas en el caso de Hispanoamérica, evolutivas en el de Brasil)" (Fernández, 1986: 309).

5 "Dice el Inca a Fernando VII: 'Pues que de injusta e inicua la conquista habéis notado de España por Bonaparte, ni te sientas ni te admires que de usurpada y furtiva igualmente yo gradúe la dominación que ha tenido en América el Español' (1977: 65). Al poner en entredicho tal comparación, Fernando VII se presenta como un sujeto del no saber ('no sé con qué fundamento a decirme te avanzas'); el desconocimiento del rey es un motivo de vieja data en el ámbito colonial. En el 'Diálogo', tal estado da lugar a la información que, a partir de esta instancia, permitirá argumentar al Inca, quien alienta a su interlocutor a consultar 'las historias"" (Altuna, 2002: 4). 
lo cual responde Atahualpa que ningún militar de esos imperios subyugadores realizó jamás actos tan crueles como los cometidos por los españoles contra los indígenas y que las excusas del rey son inválidas, de la misma manera que: “el ladrón que asalta la casa de un rico no podrá, sorprendido en su crimen, alegar su propia defensa para justificar su homicidio si despedazó al poseedor de las riquezas" (Monteagudo: 67).

Ahora, puesto que Atahualpa no acepta todo lo que Fernando VII le dice, el rey ofrece otra justificación de las atrocidades españolas. Se trata del regalo que el papa Alejandro VI le dio a Isabel de Castilla y a Fernando de Aragón -Bula Alejandrina o Inter Caetera, mediante el cual el papa les dio las tierras americanas-. Pero Atahualpa le contesta tal cual como respondieron los indígenas del Zenú a la lectura de El Requerimiento ${ }^{6}$ : no hay razón alguna para que el papa haya regalado lo que no era suyo, menos aún cuando Jesús mismo entendió a su Reino en términos de servicio y no de dominación. Tampoco sirve, según Atahualpa, el argumento de que los indígenas eran idólatras y, entonces, para extirpar dicha idolatría, había que matarlos y robarles sus tierras, pues, ¿por qué, entonces, el papa no hizo lo mismo con otras civilizaciones idólatras, a las cuales les respetó la vida, las riquezas, entre otras? Además, los españoles hicieron cosas peores que la idolatría que pretendían exterminar, sin ni siquiera haber predicado el evangelio a los indígenas. ¿No hay aquí un eco de la denuncia lascasiana? Y no pudiendo

6 "El regalo de un papá" es un aparte del texto: Ideología y praxis de la Conquista, cuya primera parte está constituida por la "Bula alejandrina", el cual es un texto redactado por el jurista español Juan López de Palacios Rubio, que radica en el permiso otorgado por Alejandro VI a la reina Isabel la Católica y al rey Fernando de Aragón, para imponer el catolicismo en Latinoamérica y conquistar dicha tierra. La segunda parte de "El regalo de un papá" es la "Interpretación indiana de la bula", que habla de la recepción que de ella hicieron los indígenas del Zenú. convencer Fernando VII a Atahualpa mediante el argumento religioso, acude al más tonto de los argumentos: los latinoamericanos han jurado fidelidad y vasallaje a España, agradecidos por las grandes felicidades de que los españoles los han colmado. A esto contesta Atahualpa, aprovechando el descuidado argumento del rey, que la sujeción de los latinoamericanos a España ha sido forzosa y que la supuesta felicidad que España le ha dado a Latinoamérica se trata más bien de ignorancia y sufrimiento, por lo cual los latinoamericanos detestan esa dominación.

La situación cambia y comienza la segunda parte del texto: Fernando VII, al no poder convencer de ninguna manera a Atahualpa, queda ahora convencido, por él, de que España ha sido muy cruel con Latinoamérica, por lo cual dice: "si aún viviera, yo mismo los moviera a la libertad e independencia más bien que a vivir sujetos a una nación extranjera" (Monteagudo: 71). Inmediatamente llega el clímax del texto, en el que Atahualpa dice que si pudiera regresar a vivir exhortaría a los latinoamericanos a buscar a toda costa su libertad, su independencia. Luego, el texto finaliza así: "I. - Idos, pues, Fernando, a Dios, que yo también a Moctezuma y otros reyes de la América darles quiero la feliz nueva de que sus vasallos están ya a punto de decir que viva la libertad" (Monteagudo: 71). De este modo le dice a quien tanto había alardeado tener vasallos voluntarios en América, que es un don nadie, que no sólo no reina en su península, sino que América tampoco le pertenece, porque ésta es, como desde siempre, de sus legítimos dueños. Gran vapuleada hacia España por parte de Monteagudo con el personaje inca.

\section{¿Para qué escribió Bernardo de Monteagudo este diálogo?}

Dicho autor empezó su carrera política el mismo año de la publicación del texto en cuestión. Él estudiaba Leyes en Charcas (actualmente Bolivia) cuando escribió el diálogo, el cual tiene la característica de estar 
completamente contextualizado con lo que estaba pasando en ese momento, lo cual nos permite identificar el nexo entre filosofía e historia: se sabía que el ejército de Napoleón Bonaparte estaba llegando a España, que Fernando VII estaba convicto en Francia y que su hermana estaba exiliada en Brasil, por cuanto era regenta de Portugal, tratando de ocupar el puesto de su hermano. En otras palabras, había en los Andes un clima de esperanza de victoria, debido a que el rey de España no estaba reinando porque el abanderado de la Revolución francesa, jaunque más absolutista!, lo tenía maniatado. Es justamente esto lo que plasma Monteagudo en su escrito: el rey español está derrotado, aunque vivo, es como si ya estuviera muerto, razón por la cual el diálogo se desarrolla en los Campos Elíseos. Y aún en ese lugar de los muertos es vencido en el debate por Atahualpa?

De este modo, el texto se difundió entre los universitarios con el fin de aportar ideas que contribuyeran al ambiente de insurrección que desembocó en las revueltas de Charcas, lugar donde estaba Monteagudo, y luego en La Paz (Altuna, 2002: 1). Recordemos que en esta época la formación en valores estuvo orientada a culturizar la población con las ideas provenientes de la Ilustración como movimiento intelectual y cultural que confrontaba el teocentrismo medieval con las ideas de libertad individual, democracia, soberanía popular, pacto social y el racionalismo como fundamento del dominio sobre la naturaleza y los hombres. Este modelo educativo produjo modificaciones en la mentalidad colectiva y por ende en la formación de valores que se impartió en la educación superior hacia finales del siglo XVIII.

7 "El destierro de Fernando VII es trasmutado en una muerte simbólica ("piadoso mi dolor, una vida me quitó tan penosa y amarga"), con la que se trataría de destacar el vacío de poder y la consecuente carencia de soberanía" (Altuna, 2002: 3).
Esta formación también estuvo orientada a concientizar a la población universitaria sobre los inconvenientes y dificultades que trajo consigo el poder de la Corona española y que finalmente originó la onda insurreccional que recorrió América Latina a finales del siglo XVIII. Los valores de obediencia y sumisión enseñados en la época de la Colonia se transformaron en rebeldía hacia la Corona española y fueron reemplazados por los ideales de libertad, igualdad y justicia. Estos conceptos se originaron en la Revolución francesa y en la denominada época de la Ilustración, ideales que se instauraron rápidamente en las nacientes repúblicas del continente americano (Botero, 2007).

Junto a esto, al leer el Diálogo entre Atahualpa y Fernando VII en los Campos Elíseos, y al leer la Carta de Jamaica, que Simón Bolívar escribió seis años después, es posible observar algo semejante a lo que acontece con los Evangelios Sinópticos; o Bolívar leyó el texto de Monteagudo, lo cual es posible debido a la amistad que tuvieron, o hubo algo así como la fuente $Q$, de donde bebieron ambos autores para realizar sus escritos. Esta conjetura surge de la siguiente similitud en la Carta de Jamaica:

«La felonía con que Bonaparte dice usted ${ }^{8}$ — prendió a Carlos IV y a Fernando VII, reyes de esta nación, que tres siglos la aprisionó con traición a dos monarcas de la América meridional, es un acto manifiesto de retribución divina y, al mismo tiempo, una prueba de que Dios sostiene la justa causa de los americanos, y les concederá su independencia».

Parece que usted quiere aludir al monarca de Méjico Moctezuma, preso por Cortés y muerto, según Herrera, por él mismo, aunque Solís dice que

8 Henry Cullen. 
por el pueblo, y a Atahualpa, Inca del Perú, destruido por Francisco Pizarro y Diego Almagro. Existe tal diferencia entre la suerte de los reyes españoles y los reyes americanos, que no admiten comparación; los primeros son tratados con dignidad, conservados, y al fin recobran su libertad y trono; mientras que los últimos sufren tormentos inauditos y los vilipendios más vergonzosos (Bolívar).

Fragmentos del Diálogo entre Atahualpa y Fernando VII en los Campos Elíseos:

I. - [Inca Atahualpa] Tus desdichas, tierno joven, me lastiman, tanto más cuanto por propia experiencia sé que es inmenso el dolor que padece quien, cual yo, se ve injustamente privado de un cetro y de una corona (Monteagudo: 65).

¿Queréis que cuando la España, por manifiesto castigo del brazo vengador del Omnipotente, sufre en su ruina y destrucción la misma suerte que ha hecho experimentar a las Américas, permanezcan y estén sujetas todavía a un Fernando que habla conmigo ahora en la región de los muertos? (70).

Comparad, pues, ahora tu suerte con la mía, la conquista de tu península con la del Nuevo Mundo, y la conducta del francés en España con la del español en América (65).

I. - [Inca Atahualpa] Si los asirios, romanos y demás hombres han sido también inhumanos, a más de no inducir bondad en un acto inicuo la ejecución de otro semejante, jamás veréis entre los asirios un soberano que, como
Huatemestu, haya sido extendido sobre ardiente y devoradora brasa de fuego por el solo vil interés de que manifestase sus riquezas. No veréis entre los romanos capitán alguno como aquel Huapetei, sacados los ojos, cortados los brazos y aserrado el cráneo9. $\mathrm{Ni}$ veréis que los griegos hicieran alguna vez como los españoles, arrancando un hijo de entre los tiernos e inocentes brazos de la madre, dándole contra el suelo y arrojándole para que sirviese de pábulo a sus hambrientos y carniceros perros. Entre todas las naciones, últimamente no hallaréis una que haya ejecutado crueldades y tiranías como los españoles, porque estas son tantas que hacen horizonte a mi vista y es imposible numerarlas (67).

Lo más importante de esta comparación es que el aparte de la Carta de Jamaica nos sirve como punto hermenéutico para interpretar la comparación realizada entre lo que le pasó a España por causa de Napoleón y lo que le pasó a América por causa de los españoles. Aunque Monteagudo habla en términos de comparación, la Carta de Jamaica nos permite interpretar que el propósito de Monteagudo no es meramente comparar al rey de España con el inca; sino también, y sobre todo, contrastarlo. El plan es mostrar la impunidad de la cual gozaban los reyes europeos, lo cual contrasta con la tortura y el asesinato que los españoles impusieron a gobernantes, según Monteagudo y Bolívar, justos. El diálogo es un recurso literario que le sirve al autor para contrastar la realidad del rey más opresor que se queja exageradamente por su nueva condición de encarcelado, con la realidad del inca oprimido, representante del pueblo latinoamericano, que realmente fue víctima. Diálogo que quizá nos permita entender el

9 No entre los romanos, pero sí entre los colombianos,. Sino, preguntémosle a Mancuso. 
porqué, gracias a la sed de libertad vivida en nuestra América a comienzos del siglo XIX, desde antes de Marx ya se preparaba un piso, una cuna, un habitáculo para recepcionar sus ideas. Diálogo que plasma la sed de libertad, que no se distingue en su temática de cualquier texto que hoy podamos catalogar como filosofía de la liberación.

\section{Crítica a la propuesta de integración social y cultural expuesta por Bernardo de Monteagudo en su diálogo}

Algo muy importante en el diálogo es la figura de Atahualpa. Monteagudo, siendo argentino, está inscrito en el incaísmo propio del Río de la Plata. Sucede que había "conexiones administrativas y territoriales entre el Virreinato del Perú y el Virreinato del Río de la Plata, a través de la sucesiva posesión de la Audiencia de Charcas" (Díaz, s. f.: 68). Al respecto, Jesús Díaz Caballero también dice:

Todos estos antecedentes históricos me permiten considerar el incaísmo como la primera ficción orientadora en la lucha por definir un centro histórico de una nación emergente, dentro de las múltiples identidades rioplatenses que se articularon en el proceso de la invención de una nueva soberanía americana en las primeras décadas del siglo XIX. En sus ciclos rioplatense y bolivariano el incaísmo sirvió como recurso retórico redentor de las masas indigenas para incorpóralas a la lucha emancipadora, justificar moralmente a los criollos frente a los peninsulares y como fuente primordial en la invención de simbolos nacionales. Por supuesto que el incaísmo también respondía a la agenda criolla de incorporar al indio del pasado para excluir al indio del presente. Particularmente en la zona del Río de la Plata el proyecto político monárquico incaísta también representó los intereses de los criollos de las provincias interiores que a través de la apropiación simbólica de la tradición dinástica incaica - cuya demanda adicional era la propuesta de nombrar a la ciudad del Cusco como capital de la nación criolla emergente- trataron de contrapesar sin éxito las fuerzas europeístas y modernizadoras del puerto de Buenos Aires (s. f.: 71) [cursiva fuera del texto].

Por consiguiente, podemos ver en Monteagudo la influencia de la idealización del Tahantinsuyu realizada por el inca Garcilaso de la Vega. El problema es que esto lleva a Monteagudo a jugar, por decirlo así, una doble moral, en el sentido de que -como lo expresa Simón Bolívar al comienzo de su Carta de Jamaica-, siendo criollo, no se identifica con los indígenas de su época, y teniendo sangre española, tampoco se identifica con los españoles, por cuanto quiere liberarse de ellos. En otras palabras, podríamos decir que todo su texto es una especie de alegato injusto, donde indica los argumentos que más le convienen a sus propios intereses de criollo, pero oculta las implicaciones radicales que tiene que mostrar su pensamiento a través de un inca: aceptar o incluir dentro del plan independentista a los legítimos descendientes del mayor imperio precolombino de Suramérica.

En este sentido, ya entendemos por qué en el diálogo no se mencionan a indígenas comunes y corrientes, sino sólo a los gobernantes (Atahualpa, Moctezuma, etc.). Tal parece que los criollos lo que querían era quitarle el puesto a los españoles y gobernar sobre los indígenas. En otras palabras, como que la independencia se trataba de un simple cambio de quien está en el poder. Independencia para criollos, no para indígenas. Y esto a costa de un llamativo documento donde un indígena es el personaje principal. 
Con base en esto se pude concluir que estamos ante un texto sumamente llamativo, escrito de tal manera que cualquier persona pudiera entenderlo y animarse a luchar por la independencia. Pero que no es tan incluyente como quisiéramos, pues en el fondo del argumento se esconde la mirada criolla respecto a los indígenas, esa que todavía se puede ver, por ejemplo, entre peruanos que se avergüenzan y se burlan de los cholos, a los cuales ven como ciudadanos de segunda clase y no los tienen en cuenta en los principales proyectos políticos, a no ser de que la temporada sea de elecciones $y$, entonces, esos millones de votos indígenas sean muy útiles. Discriminación que está desde el origen de nuestras patrias latinoamericanas, mediante la cual se ha marginado, incluso en Bolivia -a lo largo de casi toda su historia, hasta el comienzo del gobierno de Evo Morales-a la mayoría de la población, que resulta ser indígena. Criollos que buscaban conformar una oligarquía para dominar a las masas. Discurso que, en primer lugar, puede ocasionar en nosotros gran admiración, tal como los discursos de ciertos políticos en la actualidad; pero que luego de conocer sus intenciones, quizás pueda llevarnos al desánimo.

Ahora bien, en el marco de las actividades conmemorativas del Bicentenario de la Independencia colombiana, se trae a colación este texto de Monteagudo, fomentador de las ideas independentistas entre los jóvenes universitarios de su época, con el fin de advertir que, lo que le pasó a él y a muchos otros pensadores independentistas del siglo XIX, puede pasarnos ahora a los colombianos de la región Andina al excluir a personas de otras regiones del país. Los criollos, al considerarse representantes del pueblo, al creer que sus ideas independentistas eran las de todas las personas latinoamericanas, cometieron una falacia de generalizar; creyeron ser la totalidad de los latinoamericanos.

\section{Referencias}

Altuna, E. (2002). Un letrado de la emancipación: Bernardo de Monteagudo. Andes, núm. 13. Salta: Universidad Nacional de Salta. Recuperado de http://redalyc.uaemex.mx/redalyc/pdf/127/12701302.pdf

Bolívar, S. Carta de Jamaica. Recuperado de http://analitica.com/bitblio/bolivar/ jamaica.asp

Botero, C. A. (2007). La formación en valores en la historia de la educación colombiana. CLACSO.

Díaz, J. (s. f.). El incaísmo como primera ficción orientadora en la formación de la nación criolla en las provincias unidas del Río de la Plata. California: California State University. Recuperado de http:// www.ncsu.edu/project/acontracorriente/ fall_05/Diaz-Caballero.pdf

Fernández, R. (1986). América Latina y el trasfondo de Occidente. En Zea, L. América Latina en sus ideas. México: Siglo XXI Editores.

Monteagudo, B. Diálogo entre Atahualpa y Fernando VII en los Campos Elíseos. En Romero, J. L. y Romero, L. A. Pensamiento politico de la emancipación (1790-1825). Recuperado de http:// www.bibliotecayacucho.gob.ve/fba/ index.php? $\mathrm{id}=97 \&$ backPID=87\&begin at $=16 \&$ tt_products $=23$ 